\title{
CINEMA E ENSINO DE HISTÓRIA ENTRE DEBATES E PRÁTICAS
}

\section{CINEMA AND HISTORY TEACHING AMONGST PRACTICE AND DEBATES}

\author{
Vitória Azevedo Fonseca \\ Professora da Secretaria de Estado de Educação de São Paulo, Brasil \\ Doutora em História pela Universidade Federal Fluminense, Brasil \\ e-mail: vitoria.azevedo@gmail.com
}

\section{DOI:}

http://dx.doi.org/10.26512/hh.v5i9.10988

Recebido em: 21 de dezembro de 2016

Aprovado em: 14 de fevereiro de 2017

\section{RESUMO}

Tendo em vista debates sobre como usar filmes em salas de aula, especificamente no ensino de história, apresento a experiência de exibição do mesmo filme (Sonhos Tropicais, André Sturn, 2002) para diferentes turmas do $9^{\circ}$ ano do Ensino Fundamental, adotando procedimentos preparatórios diferenciados a fim de debater e defender a importância de, além da alfabetização da linguagem cinematográfica refletir também sobre o desenvolvimento da compreensão dos estudantes dos debates e diálogos "historiográficos" estabelecidos pela narrativa audiovisual para compreensão das intertextualidades presentes nos filmes. Finalizo com a análise comparativa entre as diferentes metodologias e seus diferentes resultados.

Palavras-chave: filmes; ensino de História; educação; cinema-História

\section{ABSTRACT}

In this paper, I present an experience of exhibition of the same movie (Sonhos Tropicais, André Sturn, 2002) for different classes adopting different methodologies. In one group, studants are doing activities about audiovisual language, in another group of studants the activities are focusing in understanding of the debates and dialogues "historiographical" established, and, in the last group, there is no activities before the exibihition of film. I conclude with a comparative analysis of the different methodologies and their different results.

Keywords: movies; teaching history; education; cinema-history

Um dos motivos do cinema ser um meio muito rico no processo de formação é exatamente o fato de estimular as emoções do espectador, e esta é um elemento fundamental na educação. Ao assistir um filme, todos os sentidos estão abertos para que não se perca a compreensão da história representada, por isso, a linguagem de ficção é perfeita para o ensino. Segundo Marília Franco, “Cinema e prazer são quase inseparáveis, a 
perspectiva educacional pode encontrar incontáveis possibilidades unidas a essa dobradinha." Ela acredita na linguagem audiovisual como sedutora dos sentidos: "O binômio sentidos-emoção, acionado pelo contato com as imagens em movimento, torna-se o primeiro degrau para se chegar aos níveis racionais mais altos que podem proporcionar uma aprendizagem sólida dos conceitos e sua aplicação.”2. Enquanto a educação se debate nas linguagens apropriadas para o ensino "...os meios audiovisuais continuam sendo consumidos largamente pelas pessoas, proporcionando um derrame de informação que, mesmo sem tratamento pedagógico, transforma-se em formação."3

Conforme indicou Kátia $\mathrm{Abud}^{4}$, as facilidades tecnológicas e, principalmente, as iniciativas dos professores, geradas pelo fascínio do cinema, fazem com que a exibição de filmes nas salas de aula, e nas aulas de história, seja algo crescente. Usar filmes na escola e, especificamente, nas aulas de história, além de uma prática comum disseminada, também vem sendo defendido por educadores e pesquisadores como meios de dinamizar a sala de aula para além de um formato tradicional.

No entanto, considerando a especificidade do uso de filmes no ensino de história, proponho que, para além da questão metodológica de como utilizar filmes no ensino em geral, pensemos sobre as características dos filmes exibidos, a especificidade do filme histórico e as experiências múltiplas possíveis no ambiente escolar na aprendizagem histórica.

Os debates acadêmicos em torno da questão Cinema e História nem sempre enfocam as especificidades do filme histórico e as questões específicas do ensino de história. Nesse sentido, os filmes com temáticas históricas acabam sendo deixados de lado e são comumente descartados pois carregam uma carga pejorativa em função de uma tradição de análise. As críticas no seu uso voltam-se para a possibilidade de uso ilustrativo, e, por outro lado, pesquisadores enfatizam a argumentação de Marc Ferro ${ }^{5}$ sobre a impregnação do presente em qualquer filme. No entanto, no ensino de história, entre usar o filme como ilustrativo de uma verdade do passado, e, por outro lado, limitar sua

\footnotetext{
${ }^{1}$ FRANCO, Marília. Prazer audiovisual. Revista Comunicação e Educação, São Paulo, Ano I, n. 2, 1995, p. 52.

${ }^{2}$ FRANCO, Marília. Linguagens audiovisuais e cidadania. Revista Comunicação e Educação, São Paulo, Ano III, n. 9, 1997, p. 27.

${ }^{3}$ FRANCO, 1997, p. 34

${ }^{4}$ ABUD, Kátia Maria. A construção de uma Didática: algumas ideias sobre a utilização de filmes no ensino. História [online], São Paulo, v. 22, n. 1, 2003, p. 183-193.

${ }^{5}$ FERRO, Marc. "Existe uma visão cinematográfica da história?" in: FERRO, Marc. A História Vigiada. São Paulo: Martins Fontes, 1989.
} 
abordagem ao presente, existem outras possibilidades do mesmo como dispositivo pedagógico e catalisador de aprendizagens.

De acordo com Marcia Landy a abordagem de filmes históricos, que "chegou tarde" no roll de análises dos historiadores, permaneceu durante algum tempo como uma análise de historiadores tradicionais buscando precisão historiográfica, o que acabou por tornar-se um dos maiores obstáculos para uma avaliação mais apropriada dos usos do passado no cinema.

O crítico não pode simplesmente ignorar a eliminação de determinadas informações, a distorção de certos personagens, e a mistura de fato e ficção; um crítico escrevendo sobre a história em filme deve encontrar um método para descrever e analisar esses desvios a partir de dados empíricos ${ }^{6}$.

Os trabalhos de Robert Rosenstone, Pierre Sorlin, e outros, por exemplo, procuram compreender o "texto cinematográfico" a partir dos seus próprios meios ao invés de interpretar pura e simplesmente os eventos a partir de parâmetros externos ao filme, ou, analisa-los como documentos em busca de informações sobre o presente.

Buscando ampliar a compreensão do filme com temática histórica, Robert Rosenstone $^{7}$ classifica-o em três categorias: tradicional, documental e experimental. Os filmes experimentais mesclam tanto documentários quanto ficções e possuem a semelhança de não seguirem o velho estilo naturalista de Hollywood. Para explicar como a interpretação histórica é construída nos filmes experimentais, o autor elenca alguns elementos presentes nos filmes históricos tradicionais e suas contraposições possíveis. De acordo com ele, o filme tradicional cria uma narração, com início, meio e fim embutido numa ideia de evolução humana. Da mesma forma, contra a ideia do filme tradicional no qual o passado parece fechado e simples, alguns cineastas optam, por exemplo, por filmes pensamentos, filmes teses, ou episódicos, para criar uma variedade de pontos de vista, criando, desta forma, uma imagem do passado mais ampla e complexa. Se os filmes tradicionais optam pela constante criação de emoções, os filmes experimentais podem criar representações "desdramatizadas", sem apelos emocionais. Rosenstone demonstra que

\footnotetext{
${ }^{6}$ LANDY, Márcia. The Historical Film: History and Memory in Media,. London: The Athlone Press, 2001, p. 12.

${ }^{7}$ ROSENSTONE, Robert A.. El pasado en imágenes: El desafío del cine a nuestra idea de la historia. Barcelona: Ariel, 1997
} 
existem diversas maneiras do cinema construir interpretações históricas sem limitar-se à forma de um filme histórico tradicional.

Para além de uma análise do filme como documento, alguns autores brasileiros debruçam-se sobre as relações entre as construções cinematográficas e seus diálogos com tradições historiográficas, tais como trabalhos de Eduardo Morettin, Alcides Freire Ramos ${ }^{8}$ e Vitória Fonseca ${ }^{9}$. Conforme apresentado por Fonseca ${ }^{10}$, na utilização de filmes no ensino de história, pelo menos cinco questões devem ser consideradas em função da especificidade deste objeto cultural. Em primeiro lugar, os livros didáticos reproduzem orientações pautadas por debates acadêmicos datados ${ }^{11}$, nesse sentido, a ideia de enfatizar a linguagem cinematográfica na análise de filmes não deve ser a única abordagem. Outro aspecto, é a compreensão de que filmes históricos estabelecem diálogos com diferentes tradições de interpretações dos temas que enfocam, e, além disso, pode ser considerado um tipo de "adaptação". Os filmes históricos brasileiros também podem ser inseridos na compreensão da arte com papel social, e, muitas vezes, podem apresentar interpretações do passado válidas historicamente.

Assim, podemos ampliar a noção de filme histórico e compreender suas diferentes estéticas e problemáticas ao longo do último século. Embora o passado tenha sido tematizado diacronicamente na cinematografia brasileira, com momentos de maior ou menor expressão, sempre esteve presente nas telas de cinema, mas, nem sempre em forma tradicional de "filme histórico". Para Jean Claude Bernardet, o gênero histórico no Brasil "...é quase tão antigo como o próprio cinema de ficção"12.

No início do século XX, existem referências a filmes sobre Tiradentes, D. Pedro e a independência e a guerra do Paraguai. Filmes realizados por imigrantes italianos visando sua integração à cultura brasileira, segundo Bernardet. Nas décadas de 1930 e 1940, com

\footnotetext{
${ }^{8}$ RAMOS, Alcides Freire. Canibalismo dos Fracos - Cinema e História do Brasil. São Paulo: Edusc, 2001.

${ }^{9}$ FONSECA, Vitória Azevedo da. A Monarquia no cinema: metodologia e análise de filmes históricos. São Paulo: Paco Editorial, 2017.

${ }^{10}$ FONSECA, Vitória Azevedo da. "Filmes históricos e o ensino de história: diálogos e controvérsias". Revista Locus, Juiz de Fora, v. 22, n. 2, p. 415-434, 2016. Disponível em: http://https://locus.ufff.emnuvens.com.br/locus/article/view/2915. Acesso em: 01 fev. 2017.

${ }^{11}$ FONSECA, Vitória Azevedo da. Filmes no ensino de História na visão dos livros didáticos: use com moderação. Revista Labirinto, Porto Velho, Ano XVI, v. 24, n. 2, p. 57-70, jan./jun. 2016. Tratando também da questão: PEREIRA, Lara R., SILVA, Cristiane B. Como utilizar o cinema em sala de aula? Notas a respeito das prescrições para o ensino de História. Espaço Acadêmico, Passo Fundo, v. 21, n. 2, p. 318-335, jul./dez. 2014.

12 BERNARDET, Jean Claude. "Qual é a história?". In: Piranha no mar de rosas. São Paulo: Nobel, 1982, p. 57.
} 
incentivos a realização de filmes educativos, foi criado o Instituto Nacional de Cinema Educativo (INCE), em 1937, onde Humberto Mauro dirigiu vários curtas metragens educativos, dentre eles, O Descobrimento do Brasil (1937) e Os Bandeirantes (1940) ${ }^{13}$. Na década de 1950, a mesma tendência de tematização da história como cultura e construção de uma nacionalidade está presente. No Cinema Novo, a temática histórica também aparece como forma de questionamento do presente, utilizando uma estética particular, que contesta a estética naturalista. A partir da década de 1970, o Ministério da Educação incentivou a produção de filmes com temáticas históricas, e algumas produções foram realizadas. Em meados da década de 1980, a produção cinematográfica brasileira volta-se para a temática histórica, principalmente através do gênero documentário.

A partir de um levantamento ${ }^{14}$ realizado pela autora, foi possível identificar, nos últimos vinte anos, englobando produções de 1996 a 2016, em torno de 240 filmes, entre ficções e documentários cuja temática tem alguma relação com o passado, ou, com a dinâmica do tempo na interface entre passado e presente. Analisando os títulos dos filmes e suas sinopses, observamos que nesse universo, $60 \%$ dos filmes são documentários, dos mais variados tipos e 40\% adotam a estética ficcional, com um grande número de filmes tematizando o período da Ditadura Militar. Existem variados filmes, em diferentes momentos da história do cinema brasileiro, que propõem interpretações sobre o passado, que dialogam com memórias históricas e que constroem, eles próprios, memórias ${ }^{15}$.

Um filme histórico, mesmo com seu alto grau de ficccionalização carrega, necessariamente, diversas temporalidades. Nas suas propostas, Marc Ferro aborda uma das temporalidades que pode ser analisada em todos os filmes, que é o presente. No entanto, o filme com temática histórica dialoga com o presente, mas também com a memória histórica, com tradições de representações visuais, aborda o presente das obras de base passadas, e pode, inclusive, problematizar a história.

\footnotetext{
${ }^{13}$ Sobre estes filmes veja: MORETTIN, Eduardo Victorio. Cinema e história: uma análise do filme "Os bandeirantes". Dissertação (Mestrado em Artes) - Universidade de São Paulo, São Paulo, 1994;

Os limites de um projeto de monumentalização cinematográfica: análise do filme Descobrimento do Brasil (1937), de Humberto Mauro. Tese (Doutorado em artes) - Universidade de São Paulo, São Paulo, 2001.

${ }^{14}$ O levantamento foi realizado em publicações da Ancine (http://www.ancine.gov.br/) e no portal História do Cinema Brasileiro http://www.historiadocinemabrasileiro.com.br/ .

${ }^{15}$ FONSECA, Vitória Azevedo da. História escolar, cinema brasileiro e história pública: caminhos de uma memória. Revista Observatório, Franca, v. 3, n. 2, p. 92-112, 2017.
} 
Éder Cristiano Souza, analisando o cinema a partir de referenciais da educação histórica, propõe como abordagem, para além da análise do filme como documento, ou, como forma de escrita da história, uma terceira forma de análise.

Temos então dois enfoques principais: os filmes como documentos históricos, aos quais se recorre para aprofundar a reflexão sobre o período em que as películas foram produzidas. Os filmes como discursos sobre a história, aos quais se constroem críticas historiográficas sobre suas abordagens históricas. Mas há um terceiro enfoque importante, que deve ser também levado em consideração, que se trata de entender os filmes como agentes da história. ${ }^{16}$.

Esse terceiro enfoque está relacionado a compreender de que maneira o cinema contribui para construção de uma cultura histórica, e, no ambiente escolar, compreender as leituras dos filmes históricos realizadas pelos alunos e professores. $\mathrm{O}$ autor defende a importância de pesquisas para compreender de que maneira são realizadas as leituras dos filmes, tanto por parte de estudantes quanto por parte de professores.

Considerando essas reflexões, e, principalmente, questionando as orientações presentes em livros didáticos, a experiência apresentada neste texto dialoga com os debates sobre Cinema e História, incorporando aspectos relacionados ao ensino de História. Os livros didáticos, bases ainda importantes na prática docente em diferentes lugares do país, em geral, orientam aos professores que utilizem os filmes no ensino de História, mas, com algumas ressalvas, como aponta a análise de Fonseca ${ }^{17}$. Pautados cada vez mais por diálogos com a tradição acadêmica em relação à análise fílmica, os livros didáticos acabam por disseminar, acriticamente, algumas premissas que são historicamente construídas no campo cinematográfico. Assim, a utilização de filmes no ensino de História é geralmente permeado por interdições. Há quem defenda que não se deva exibir o filme sem uma preparação, sem que os alunos pesquisem antes, etc.

Essa ênfase constante dada pelas orientações de uso de filmes em sala de aula, na necessidade, quase imprescindível, de direcionar a leitura dos alunos, pode não ser aplicável e nem interessante em toda e qualquer situação. Em alguns casos, pode ser muito mais interessante observar as leituras realizadas pelos alunos a partir de suas próprias percepções. E, a partir daí, iniciar o processo de ensino-aprendizagem. Nesse aspecto, o

\footnotetext{
${ }^{16}$ SOUZA, Éder Cristiano. Cinema e didática da história: um diálogo com o conceito de cultura de Jörn Rüsen. História Revista, v. 17, n. 1, 2012, p. 19.

${ }^{17}$ FONSECA, 2016.
} 
filme pode servir como catalizador de aprendizagem e também como "sensibilização". ${ }^{18}$

A partir da inquietação sobre metodologias de utilização de filmes com temática histórica na sala de aula, propus uma atividade comparativa na intenção de observar as diferentes respostas dadas pelos estudantes. Nesse sentido, neste texto, apresento considerações sobre, especificamente, o uso de filmes com temática histórica no ensino de história e possibilidades de utilização em sala de aula a partir de uma experiência realizada com alunos do $9^{\circ}$ ano.

\section{FILMES NA SALA DE AULA: E AGORA?}

Aqueles que possuem a prática de exibir filmes aos alunos sabem que esse uso do cinema é uma experiência temporal, tanto para os jovens quanto para os docentes, na qual vai se construindo aos poucos uma análise crítica e proveitosa. Ou seja, nem o primeiro filme exibido pelo professor, nem a primeira exibição para os alunos, farão milagres. Cada professor vai aprendendo com sua experiência, criando seus próprios métodos a partir das suas possibilidades. Por outro lado, dependendo do grupo de alunos para o qual o filme é exibido o professor poderá encontrar diferentes possibilidades de aprendizagens.

Assim, partindo da proposta de compreender as leituras dos alunos é importante desenvolver, além da teoria sobre os próprios filmes, também análise das possibilidades geradas nas exibições. Apresento abaixo uma experiência inicial que, no entanto, nos aponta para algumas reflexões. Diante das diversas possibilidades, tornava-se premente refletir sobre as respostas dadas pelos estudantes a diferentes metodologias de preparação ao filme. Na prática de sala de aula, foi possível experimentar diversas formas de utilizar os filmes no processo de ensino/aprendizagem e, a partir disso, vários questionamentos foram sendo gerados. Dentre eles estavam se os alunos deveriam ou não ser preparados para assistir ao filme e de que maneira, enfatizando quais aspectos. Decorrente disso, a experiência relatada aqui foi proposta.

O filme escolhido foi Sonhos Tropicais (André Sturn, 2002). Em meio a um surto de dengue, com os estudantes desenvolvendo percepções sobre o processo de proliferação de doenças e a necessidade de intervenção do poder público, foi escolhido esse filme pois tematiza o problema da saúde pública no Rio de Janeiro no início do século XX, que

${ }^{18}$ FONSECA, 2016, p. 67 
culmina na Revolta da Vacina, tema que também fazia parte do planejamento daquele bimestre, naquelas turmas.

Com três diferentes classes, foram três diferentes tratamentos do mesmo filme. A primeira turma foi preparada para assistir ao filme, com ênfase nas questões da linguagem cinematográfica. A segunda, foi preparada a partir das questões relacionadas ao contexto histórico e as interpretações historiográficas sobre o evento retratado no filme, e, por fim, a terceira turma não foi preparada e assistiria ao filme simplesmente.

\section{PREPARANDO PARA A LINGUAGEM CINEMATOGRÁFICA: ESPECIFICIDADES}

A realização de um filme de ficção vai além da criação de personagens e elaboração de tramas que configuram um drama. As personagens são vividas por atores que se pronunciam, projetam falas, dialogam com outras personagens, se posicionam, e recriam a ficção escrita por um dramaturgo ou roteirista em diálogo com as suas características físicas e as suas vivências. Esta personagem vivida por um ator ou atriz, vive em espaços que podem ser extensão da sua personalidade e do seu desejo ou então que recriam o clima do filme. Estes espaços são cenários criados com uma finalidade expressiva levando em consideração texturas, cores e volumes. Por sua vez estes cenários são iluminados, luz concebida, normalmente, de acordo com a premissa do filme com a sua proposta estética e estilística. Cada luz tem seu código expressivo. Além da personagem com seu figurino, o cenário e a luz, temos a mis en cene que é a encenação, a maneira como os personagens se movimentam na cena e ainda a câmera que olha. Este olhar da câmera revela enquadramentos, movimentos, focos, angulação, escolhas. O que será mostrado? De que ponto de vista? Plano Geral, plano detalhe, plano médio? E os movimentos de câmera? Tudo narra num filme. Cada um destes elementos expressivos de um filme possui sua maneira particular de operar, mas ao mesmo tempo, quando em diálogo com todas as artes que compõem um filme, um aspecto influencia o outro.

A montagem também exerce um papel significativo na produção de sentido e organização da narrativa e do drama. Existem várias formas de montar um filme o que ocorre de acordo com a sua proposta. Para alguns autores a especificidade do cinema está exatamente na montagem que é o que possibilita a construção de sentido.

Assim, quando manuais escolares mencionam a necessidade da análise da linguagem cinematográfica, em termos genéricos, quando da utilização de filmes no ensino 
de história, a afirmação pura e simplesmente pode não gerar ecos na prática docente considerando existir uma complexidade nesta afirmação que requer, muitas vezes, uma formação específica. Desta maneira, a partir de referenciais de análise fílmica, podemos afirmar que não existe uma "linguagem cinematográfica" geral a ser analisada, mas, elementos de uma linguagem especificada em determinado filme, de determinada maneira, gerando múltiplos efeitos.

Por isso, defendo que, ao analisarmos elementos técnicos da linguagem cinematográfica que sejam aliados forma e conteúdo, considerando não apenas a estética, mas, o contexto no qual se insere e os significados interpretativos que geram. Portanto, em cada filme, podem ser eleitos para análise elementos mais significativos para a construção da interpretação histórica que o professor pretenda enfatizar.

No caso de Sonhos Tropicais (André Sturn, 2002), a construção das personagens e suas narrativas paralelas foram eleitos elementos significativos considerando a argumentação, presente no filme, para a explicação das causas da Revolta da Vacina, momento culminante do filme. Assim, ao selecionar o trabalho com a linguagem cinematográfica, foram eleitas a narrativa fragmentada e os vários personagens. Os elementos ficcionais não estão dissociados dos conceitos históricos que norteiam um filme. Não pretendemos defender aqui a existência de uma linguagem pré-estabelecida e decodificada do cinema. As soluções encontradas e incorporadas em cada filme estão de acordo com as suas especificidades e fazem sentido no seu contexto.

Tendo em vista estas questões, com a primeira turma, selecionada para ser preparada para ver o filme a partir de um enfoque em elementos da linguagem cinematográfica, foram realizadas diversas atividades com esta finalidade. Atividades voltadas para identificação de aspectos técnicos da linguagem cinematográfica, tais como enquadramento e movimentos de câmera e também enfatizado o aspecto relevante para a compreensão do filme que está relacionado à narrativa e a construção dos personagens. As atividades envolveram recortes de imagens, registros com celulares, criação de narrativas ficcionais a partir da criação de conflitos para as personagens. Em seguida, foi exibido o filme, divido em duas partes, e, ao final, os alunos responderam ao questionário, participando, em seguida, de um bate-papo.

A ênfase na análise da construção de personagens se justifica em função da especificidade do filme. Em outros casos, são analisados movimentos de câmera, o cenário, 
a música, as falas, enfim, esses elementos são selecionados, como mencionado acima, em função de cada caso em particular.

O filme Sonhos Tropicais (André Sturn, 2002) é homônimo do livro, do qual é uma anunciada “adaptação”, de Moacyr Scliar (1992) sobre o médico sanitarista Oswaldo Cruz. O filme, diferente do livro, traz diferentes personagens que ocupam papéis importantes na narrativa. O livro tem uma narrativa complexa na qual os tempos presente e passado se misturam. O narrador escreve para o próprio Oswaldo Cruz sobre a sua experiência de ser procurado para falar sobre ele, Oswaldo e, grande parte do livro se ocupa em relatar a sua vida, sempre direcionado ao próprio. Ao compararmos essa estrutura narrativa com o filme percebemos modificações significativas.

Em primeiro lugar, o filme narra trajetórias paralelas entre dois personagens: Oswaldo Cruz e Esther, uma mulher "polaca" que chega ao Rio de Janeiro do fim do século XIX, prometida para casamento que encontra uma realidade muito diferente da imaginada pois é obrigada a trabalhar num bordel, prostituindo-se. Essa personagem aparece em alguns poucos momentos no livro nos quais sua vida cruza a de Oswaldo Cruz. No entanto, outros personagens se cruzam e entrecruzam em uma narrativa cheia de elementos. O personagem de Amaral, um "malandro" carioca e amante pobre de Esther, também aparece em segundo plano no livro e é focalizado no filme. Assim, podemos dizer que os personagens centrais dessa história são Oswaldo Cruz e Esther. Mas o foco do filme não fica apenas neles.

Outros personagens populares aparecem. Prata Preta é apresentado com um filho doente sendo levado para o hospital, onde esbarra com Mariano, um operário que se revolta por não ter sua esposa atendida: operário e negro vivem a mesma miséria e descaso. Durante a narrativa, três senhores, provavelmente jornalistas, fofocam sobre as notícias do Rio de Janeiro e informam o espectador sobre questões contextuais. Vicente de Souza organiza reuniões no Centro das Classe Operárias, e, clandestinamente, participa de reuniões de militares descontentes, dentre eles Travassos e também Teixeira Mendes, um positivista. Este grupo é representado na narrativa como conspiradores.

$\mathrm{Na}$ trajetória de Cruz, ele combate epidemias, cria o laboratório em Manguinhos. As narrativas paralelas se entrecruzam. Com imagens documentais, são apresentadas notícias da época: R. Alves toma posse, pessoas pegam febre amarela, capoeiras são presos, Pereira Passos inicia a reforma do Rio de Janeiro. Cruz é convidado pelo Ministro Seabra para ocupar o cargo da Segurança Pública.Oswaldo Cruz apresenta ao Presidente 
Rodrigues Alves o método de Cuba de extermínio dos mosquitos. Os jornalistas falam que Passos e Cruz governam a cidade e fazem o que querem. Cruz orienta os agentes de saúde que em seguida começa a invadir casas e abordar de forma violenta a população. $\mathrm{Na}$ casa atingida está a esposa de Prata Preta. Os jornalistas falam da charge "Oswaldo Cuba". No entanto, o método tem sucesso. Em uma cena, Alves lê a noticia para Cruz de que não existe mais a febre amarela no Rio. Cruz fica apreensivo, ainda precisam acabar com a peste. Propõe a extinção dos ratos. O método é comprar ratos da população. Neste episódio, Amaral encarna a pessoa que criou ratos para vender. Fato este noticiado pelos jornais da época, no Rio de Janeiro.

$\mathrm{Na}$ narrativa de Esther, ela passa de uma estrangeira que não aceita a situação de estar obrigada a se prostituir em um bordel a uma administradora de bordel, sob a proteção do chefe de polícia Camargo. No entanto, ela é surpreendida por ele na cama com Amaral, seu amante malandro e pobre. Em função disso, o chefe de polícia transforma os dois em seus inimigos. No contexto da reforma urbana, o bordel administrado por Esther é demolido para dar lugar a uma avenida e ela, e sua amiga, ficam sem espaço para trabalhar em função da inimizade com o chefe de polícia.

Perambulando pelas ruas, a amiga de Esther é contaminada com varíola. É levada para o hospital, onde morre. No hospital, Esther encontra com Oswaldo Cruz e a comitiva com o presidente e deputados, dentre eles, Varela. Esther é voluntária para aplicação da vacina. No entanto, os políticos discutem. Varela discorda e promete oposição. (Uma das enfermeiras menciona o boato de que a vacina seria feita com pus de vaca, e é repreendida). Os jornalistas ridicularizam Cruz, a vacina e sua lanceta. Fazem chacotas obscenas. Esther, sem alojamento, vai trabalhar no boteco do português, sr. Romão, frequentado por Prata Preta, Amaral, e, na revolta, torna-se um ponto de encontro.

No governo, discutem o Regulamento de Cruz, que tem forte oposição. Vicente fala ao povo para resistir ao governo e à vacina. Um homem, preocupado com o filho que tomou a vacina vem conversar com Vicente, que lhe avisa não ter problema nenhum e que não estão contra a vacina, mas contra o governo. Varela também discursa ao povo e fala da invasão de domicílios e falta de segurança das mulheres. Ocorre o primeiro confronto com a polícia. Em paralelo, os militares também sugerem um levante. Iniciam-se confrontos em diferentes lugares da cidade.

Os diversos personagens se encontram na revolta. De um lado, Prata Preta, Amaral, Esther, Mariano; de outro, Cruz tentando explicar a importância da vacina; Vicente 
de Souza, instigando a população, com apoio dos militares, de ir contra o governo, e, membros do governo tentando manter o poder.

Inicialmente, a resistência no morro segue firme, mas, ao final, são derrotados pelas tropas do governo. Na rua, no dia seguinte, vemos vários mortos e Prata Preta sendo espancado por policiais. As legendas finais informam sobre o destino de Oswaldo Cruz e dos participantes da Revolta, como Prata Preta, que são enviados para o Acre.

Assim, o filme, com variados personagens e trajetórias que se cruzam na cidade, não é de simples compreensão. No entanto, dramaturgicamente apresenta diversos elementos que podem ser debatidos com os estudantes, que, aliados a uma leitura crítica da historiografia, pode levar a uma análise mais interessante.

\section{PREPARANDO PARA ANÁLISE HISTORIOGRÁFICA}

O filme, apresentado acima, não pode ser analisado sem o estabelecimento de uma relação com a historiografia sobre o tema. Conforme é defendido em Fonseca ${ }^{19}$, os filmes históricos estabelecem diálogos com as tradições de interpretações dos temas que enfocam. Assim, uma parte significativa da análise a ser empreendida em uma aula de história diz respeito a compreender o filme como uma forma de interpretação do passado, uma argumentação textual em forma de narrativa ficcional cinematográfica que dialoga com interpretações anteriores.

Considerando ser este aspecto bastante significativo, a segunda turma contou com o desenvolvimento de atividades ligadas à preparação para compreensão de aspectos históricos da Revolta da Vacina e a leitura de autores que realizaram interpretações sobre ela. Assim, os alunos tiveram acesso a reproduções de trechos de jornais que noticiaram a revolta, às charges publicadas sobre Oswaldo Cruz, e, principalmente, tiveram acesso à sínteses das ideias dos historiadores Sidney Chalhoub ${ }^{20}$; Nicolau Sevcenko ${ }^{21}$ e José Murilo de Carvalho ${ }^{22}$, a partir do qual foi realizado um debate. Neste debate, com envolvimento ativo dos estudantes, estes apresentaram suas opiniões sobre as causas da revolta. E, no

\footnotetext{
${ }^{19}$ FONSECA, Vitória Azevedo da. "Filmes históricos e o ensino de história: diálogos e controvérsias". Revista Locus, Juiz de Fora, v. 22, n. 2, p. 415-434, 2016. Disponível em: http://https://locus.ufff.emnuvens.com.br/locus/article/view/2915. Acesso em: 01 fev. 2017.

${ }^{20}$ CHALHOUB, Sidney. Cidade febril. Cortiços e epidemias na Corte Imperial. São Paulo: Companhia das Letras, 1996.

${ }^{21}$ SEVCENKO, Nicolau. A revolta da vacina - mentes insanas em corpos rebeldes. São Paulo: Brasiliense, 1984.

${ }^{22}$ CARVALHO, José Murilo de. Os bestializados: o Rio de Janeiro e a República que não foi. São Paulo: Companhia das Letras, 1987.
} 
geral, aderiram à argumentação de Sevcenko (chamado de Nicolau, pelos alunos), que defende, em seu texto, que a Revolta da Vacina foi um pretexto para a grande insatisfação popular em relação às ações do governo.

Nicolau Sevcenko, em seu livro paradidático $A$ Revolta da Vacina faz um relato da revolta como um clamor do povo por justiça. Segundo ele, essa revolta "se constituiu numa das mais pungentes demonstrações de resistência dos grupos populares do país contra a exploração, discriminação e o tratamento espúrio a que eram submetidos pela administração pública nessa nossa fase da história" ${ }^{23}$.

Sidney Chalhoub, em seu livro Cidade Febril, analisa, em um dos capítulos a questão da vacina na qual estava envolvida a revolta. Segundo o autor, os historiadores anteriores não se aprofundaram na história da própria vacinação e a relação que a população estabelecia com ela. Este item torna-se de vital importância para compreender a rejeição à vacina que foi justificativa para a revolta. Sua análise é ampla e rica, no entanto, tem pouca ressonância no filme analisado.

Dentre os historiadores apresentados, o livro de Scliar e o filme de Sturn seguem a tendência de José Murilo de Carvalho que argumenta sobre a fragmentação dos formadores da revolta, a presença e manipulação dos militares florianistas, além da falta de controle do povo depois de iniciada a revolta.

Considerando que o filme, além de enfocar os dois personagens Oswaldo Cruz e Esther, também acompanha os dramas vividos por outros personagens: o malandro Amaral, o operário Mariano, o negro Prata Preta, além de apresentar outros interesses de grupos sociais tais como militares florianistas, políticos opositores, jornalistas, podemos dizer que apresenta argumentação semelhante a elaborada por José Murilo de Carvalho ${ }^{24}$ sobre a fragmentação da revolta. Assim, a fragmentação narrativa em vários personagens, de diferentes camadas sociais assume um caráter significativo na interpretação historiográfica.

Segundo José Murilo, a composição da revolta foi fragmentada e variou de acordo com o seu desenrolar. No início eram vários componentes, desde operários, comerciantes, estudantes, militares. Com o fracasso do golpe militar a liderança passou aos operários e classes"perigosas", com os redutos em Sacramento e Saúde. Quanto aos motivos da revolta, segundo ele, há um consenso de que se preparava um golpe contra o poder pelos

\footnotetext{
${ }^{23}$ SEVCENKO, 1984, p. 5.

${ }^{24}$ CARVALHO, 1987.
} 
antigos florianistas. No entanto, não havia o estopim para deflagrar a revolta. O estopim foi a vacina, ou seja, no final das contas, um pretexto para a revolta. Nesse sentido, as interpretações de Sevcenko e Carvalho, se aproximam. E esta foi a visão aceita pelos alunos, em termos genéricos. Eles assistiram ao filme, com uma ideia preconcebida de que houve uma revolta contra o governo tendo como pretexto uma vacinação obrigatória.

\section{CRÍTICA À LEITURA INDUZIDA: ASSISTIR SEM PREPARO}

A partir da desconfiança da insistência em "preparar" os estudantes para assistir aos filmes em grande parte dos manuais escolares foi proposto, em uma das turmas, que os alunos assistissem ao filme sem que houvesse qualquer preparação, seja ela voltada para análise da linguagem cinematográfica, seja ela voltada para análise dos aspectos historiográficos do filme.

Conforme defende Souza, é fundamental, para o ensino de História, a atenção para outros aspectos da utilização de filmes.

Todo o potencial de análise fílmica não pode ser explorado sem uma pesquisa aprofundada das narrativas históricas dos jovens alunos, sobre como os filmes históricos se relacionam com o conhecimento histórico. A compreensão das ideias históricas destes sujeitos, diretamente envolvidos no processo educativo, pode direcionar compreensões sobre as formas e funções que tomam os filmes históricos na formação e na cultura históricas. ${ }^{25}$

Nesta proposta, a opção pela exibição sem preparação partiu da compreensão da necessidade de observar, sem interferência do professor, a leitura que aqueles jovens fariam de um filme a partir da própria bagagem, da sua própria formação histórica, até aquele momento, e, principalmente, observar a capacidade comunicativa, entre os jovens, daquele filme em particular. Assim, optou-se por utilizar o filme como uma espécie de pretexto para que os jovens expusessem suas ideias prévias no contato com uma produção cinematográfica. Esse aspecto torna-se importante e mais amplo se observado a partir dos referenciais do processo de construção de cognição histórica.

A compreensão das formas com que se processam os entendimentos de tais leituras, por parte de professores de história e de jovens alunos, é o problema que se coloca. $\mathrm{O}$ trabalho com filmes históricos poderia se focar no aluno, no seu processo de cognição histórica situada (Schmidt,

${ }^{25}$ SOUZA, 2012, p. 28. 
2009(2), localizando como este processo cognitivo se relaciona com o trabalho a partir deste artefato cultural. ${ }^{26}$

Assim, foi proposto, neste trabalho, que os estudantes pudessem expor suas impressões sobre o filme exibido sem que houvesse qualquer direcionamento por parte da professora. Os cuidados tomados foram o espaço, a visibilidade e a qualidade sonora da exibição, bem como a fruição sem cortes do filme para que houvesse, da melhor maneira possível, concentração dos estudantes em relação ao filme em si. Vejamos abaixo a análise das respostas dadas por eles.

\section{ANÁLISE DAS RESPOSTAS}

Após a exibição, os alunos responderam, sem direcionamento, à algumas questões, por escrito. $\mathrm{Na}$ análise das respostas, foi possível fazer uma sondagem sobre a compreensão de cada grupo e os possíveis impactos da preparação na visão de cada um em particular e suas diferenças. A partir das respostas, foram construídos os gráficos apresentados abaixo.

Os gráficos foram montados a partir de respostas abertas, portanto, em alguns casos, existe a condensação de respostas em conjuntos. O grupo 1, equivale ao grupo cuja preparação esteve voltada para a linguagem cinematográfica, o grupo 2 , o que teve a preparação voltada para questões da historiografia e, por fim, o grupo 3, que não passou por preparação.

A primeira questão, visava sondar a visão geral que os alunos construíram sobre o filme. Assim, a pergunta foi "Qual o assunto, na sua opinião, abordado pelo filme”?

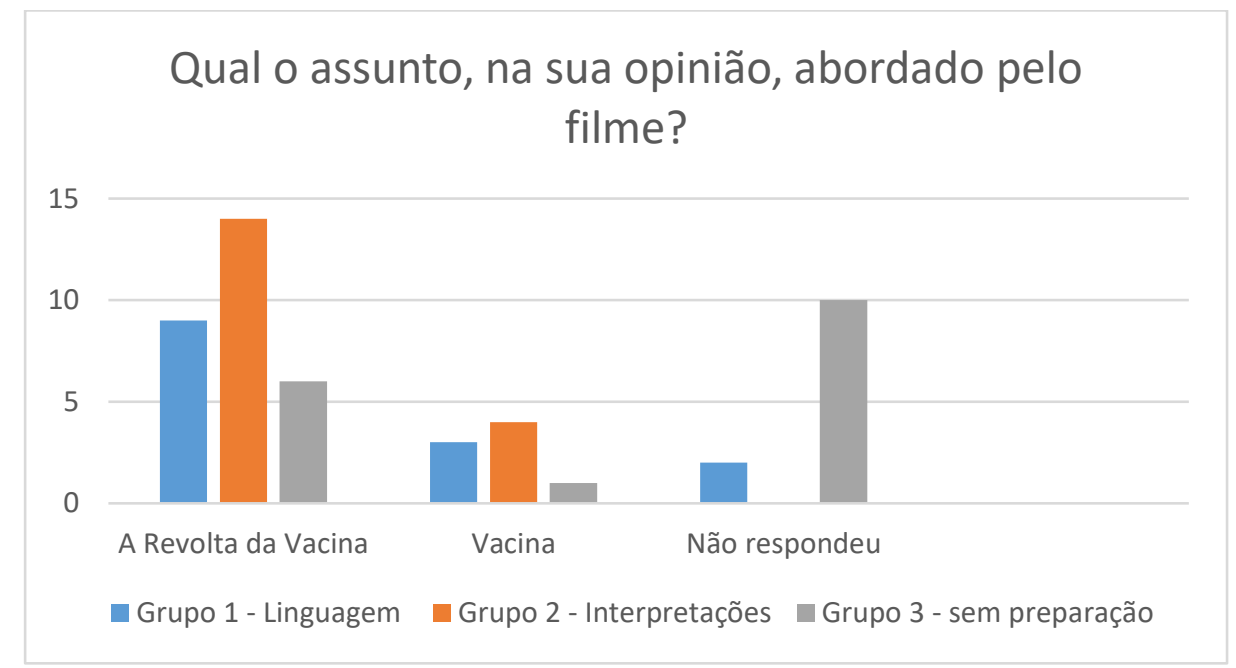

${ }^{26}$ SOUZA, 2012, p. 28. 
Gráfico 1 - Elaboração própria. Respostas dos alunos da EE Arthur Cyrillo Freire (Sorocaba, SP), em 2015.

Para essa primeira questão, percebemos que os alunos do grupo 2 identificam com mais facilidade o filme com a Revolta da Vacina, e, um número maior de alunos do grupo 3não foram capazes de identificar o assunto do filme, respondendo simplesmente "não sei" ou deixando em branco. Alguns alunos responderam que o assunto do filme era a vacina.

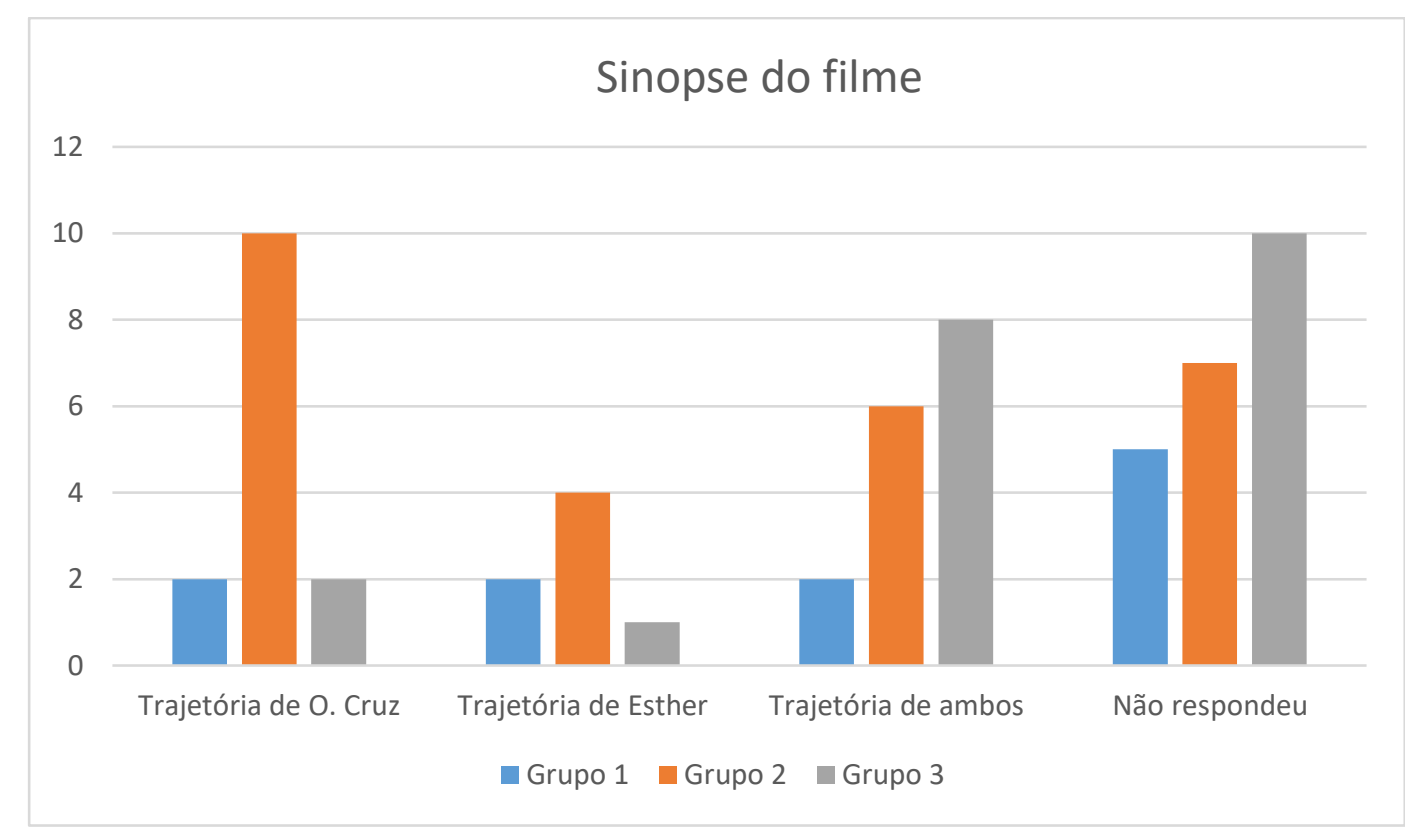

Gráfico 2 - Elaboração própria.

Com objetivo de identificar a capacidade dos alunos em produzir uma síntese, textualmente, foi solicitado que escrevessem uma pequena sinopse. Organizando as respostas nos enfoques mais comuns foi possível apresenta-las no gráfico acima, que, nos indica, em primeiro lugar, que o grupo 2 apresentou uma visão mais uniforme e focado nas trajetórias de Oswaldo Cruz e/ou de Esther como eixo narrativo do filme. Já o grupo 1, apresentou uma visão mais pulverizada e pouco uniforme em relação à narrativa com observação de outros aspectos para além dos dois personagens principais, citados acima. Ou seja, ao enfocarem a variedade de personagens não conseguiram sintetizar a narrativa. Já os alunos do grupo 3 apresentaram dificuldades em identificar um eixo principal da narrativa do filme e focou a sinopse na citação de episódios, sem uma coerência entre eles.

A terceira questão está relacionada na observação da capacidade dos alunos identificarem os personagens do filme, assim, foi enunciada como "Quais são os personagens principais do filme?". A pergunta buscava sondar a capacidade de 
identificação de um elemento fundamental numa narrativa cinematográfica, que são os personagens.

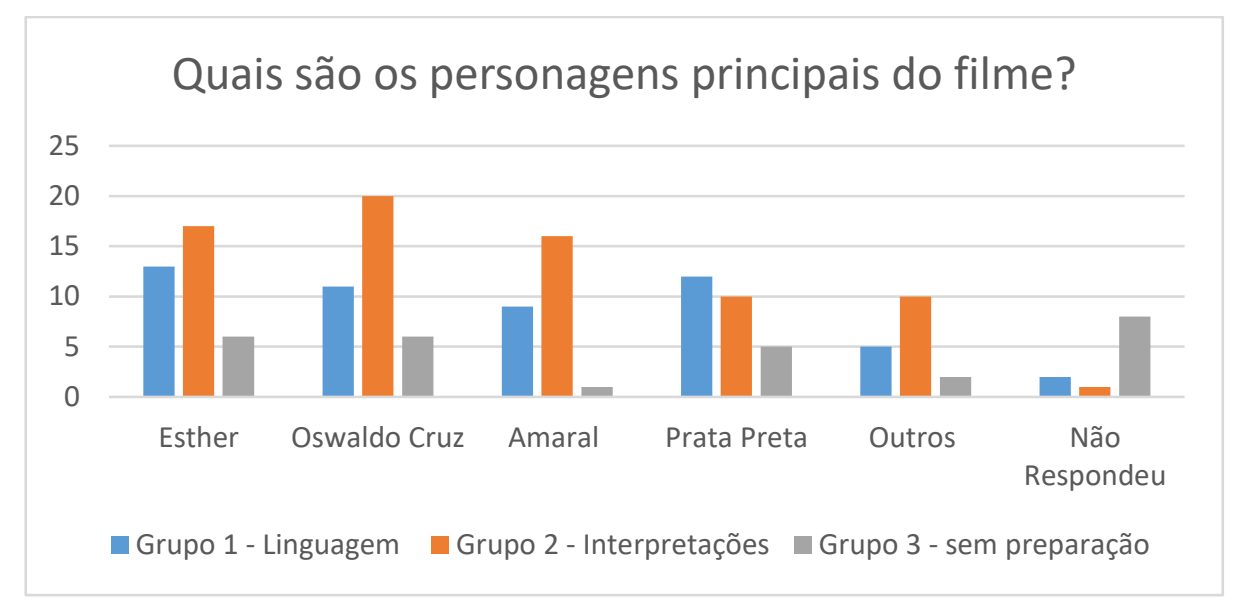

Gráfico 3 - Elaboração própria. Idem.

Através da análise das respostas, foi possível observar que a variedade de personagens foi notada pelos estudantes. O grupo 1 identificou vários personagens, focando em Esther, Oswaldo Cruz, Amaral, Mariano, Prata Preta e Vicente de Souza. Já o grupo 2, apresentou uma visão mais difusa dos personagens, com centralidade em Esther, Oswaldo Cruz, Amaral e Prata Preta. No entanto, alguns alunos confundiram os historiadores estudados previamente com os personagens do filme. Já o grupo 3 apresentou grande dificuldade em identificar personagens, e, portanto, muitos não responderam.

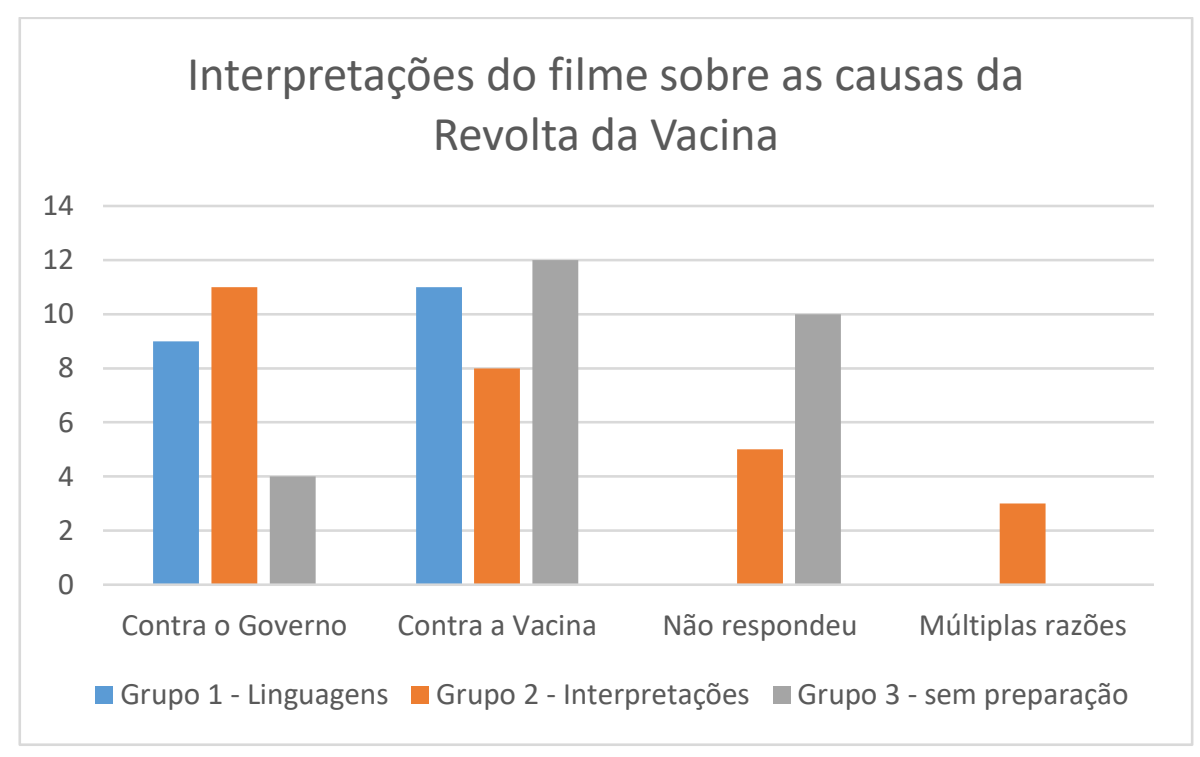

Gráfico 4 - Elaboração própria. Idem.

Em relação à última pergunta, que diz respeito às interpretações sobre as causas da Revolta da Vacina, o grupo 1 ficou dividido entre a vacina como causa e como pretexto, 
sendo que mais alunos identificaram a vacina como causa. Algo semelhante ocorreu com o grupo 2, mas, nesse caso, mais alunos identificaram a vacina como pretexto e, curiosamente, alguns alunos apontaram para uma visão mais complexa, indicando que a revolta teria variadas causas. Já no grupo 3, a maior parte dos alunos que respondeu optou pela vacina como causa, e, além disso, grande número não respondeu à pergunta.

\section{CONSIDERAÇÕES FINAIS}

No geral, o que podemos perceber, foi que a preparação acabou direcionando o olhar dos alunos nos grupos 1 e 2. Nesse sentido, o filme acabou sendo menos uma experiência particular e acabou funcionando como um tipo de "confirmação" do que havia sido trabalhado. Enquanto os alunos do grupo 3, que não tiveram nenhuma preparação mostraram interpretações mais independentes, e, ao mesmo tempo, demonstraram maior dificuldade em acompanhar a argumentação do filme.

Enfocando aspectos da linguagem cinematográfica, como resultado, foi possível perceber que no geral os alunos conseguiram identificar as trajetórias dos personagens em seus diferentes conflitos. No entanto, na pergunta referente ao ponto de vista do filme sobre a Revolta da Vacina, os alunos tiveram dificuldade em identificar e a maior parte não conseguiu responder ao que fora perguntado. O olhar, a partir da preparação enfocando as personagens, acabou sendo direcionado para observar a multiplicidade de personagens e a dispersão das trajetórias, características do filme. No entanto, isso dificultou a construção de um olhar sintético na análise da revolta da vacina como evento catalizador e unificador das trajetórias. Ou seja, foi possível levar os alunos a observarem as diferentes trajetórias de maneiras dispersas, sem, no entanto, construir um olhar que buscasse uma unidade entre elas.

Em relação ao grupo 2, após a exibição do filme, foi possível notar, nas variadas respostas, uma ênfase em tópicos abordados e enfatizados em sala de aula, antes do filme. Ou seja, o trabalho de preparação em relação ao conteúdo que seria tematizado pelo filme teve um efeito de direcionar o olhar dos alunos, enfocando o evento final. É interessante que apenas alguns itens, que indicavam uma outra interpretação para a revolta, foram enfatizados pelos alunos, sem, no entanto, alterar a intepretação geral, aparentemente já formada antes do filme. Um exemplo foi uma cena citada na qual uma enfermeira fala que a vacina era feita de pus de vaca que tocou a sensibilidade dos estudantes e que poderia indicar uma causa para a revolta. No entanto, os alunos, no geral, construíram uma imagem 
de que a revolta popular foi contra o governo. A maior parte dos estudantes identificou a vacina como tendo sido apenas um pretexto para a revolta. E, chamou a atenção a ênfase dada às ações truculentas do Estado, no filme. Nesse caso, podemos perceber que a preparação dos alunos acabou por direcionar a leitura dos mesmos sobre as interpretações das causas da revolta e a atuação do governo.

Mesmo apresentando diferentes "interpretações" para um mesmo "evento histórico", e explicando esses diferentes pontos de vistas, dependendo de cada autor e, para completar, mesmo o filme abrindo a possibilidade para as diferentes interpretações para as causas da revolta, nas suas narrativas os alunos optaram por explicações únicas como se não fosse possível aceitar as diferentes explicações.

No que diz respeito às respostas do grupo 3, os resultados, após a exibição, foram interpretações mais independentes e menos uniformes e, ao mesmo tempo, mais criativas. Foi possível perceber diferentes níveis de compreensão de aspectos básicos da narrativa do filme demonstrando, talvez, uma certa inadequação entre a linguagem do filme e a percepção dos estudantes.

Dentre as causas para a revolta mais citada por esse grupo esteve que a revolta teria sido causada pelo medo de contrair a doença a partir da vacina. Nessa percepção mais livre, foi possível observar diferentes construções narrativas para dar sentido àquilo que haviam assistido, interpretações que, se não podem ser consideradas "corretas" dentro de uma análise mais estreita, indicam exercícios mentais de tentativas de compreensão do que assistiram. Cito aqui alguns trechos dos textos dos alunos:

"O médico Oswaldo Cruz cria uma vacina para prevenir as doenças que
os ratos transmitiam. Pessoas se voluntariaram para testar a vacina. A
maioria dos voluntários morreram, apenas uma sobreviveu. E por isso o
governo quis que povo tomasse a vacina e pelo fato de muitos terem
morrido um grupo começou a achar que o governo queria matar o
povo..." (J.P. $8^{\mathrm{a}} \mathrm{A}$ )"os 'pobres' achavam que a culpa era da república por
querer eles mortos por isso eles se revoltaram" (L.E. - $8^{\mathrm{a}} \mathrm{A}$ )"O povo
achava que tomando a vacina iam contrair a doença em vez de curar"
(B.C.- $8^{\mathrm{a}} \mathrm{A}$ )"A revolta ocorreu porque o povo tinha medo, achavam que
se tomassem a vacina, morreriam" (A.C. $8^{\mathrm{a}} \mathrm{A}$ )

A partir desse trecho, foi claro que o exercício realizado pelos alunos que não passaram por preparação foi mais criativo e mais ativo do que os outros grupos, apesar dos outros grupos terem tido outros tipos de compreensões. 
Nesse sentido, a partir das análises apresentadas, é possível considerar que, diferentes metodologias levarão a diferentes experiências na utilização de filmes no processo de ensino/aprendizagem. Assim, o professor pode considerar as especificidades dos filmes, dos alunos e dos objetivos da sua proposta e experimentar possibilidades que enriqueçam sua prática e a aprendizagem, construindo uma trajetória múltipla que não se limite a reproduzir prescrições, e que, ao contrário, possa compartilhar suas práticas e enriquecer o conhecimento sobre a utilização de filmes no ensino de história, a partir das próprias práticas escolares. 